\title{
Uso de resíduos de couro wet-blue como componente de substrato para plantas
}

\author{
The use of residues of wet blue leather as a growing media component
}

\author{
Rafael Henrique Schü̈̈r Daudt ${ }^{\mathrm{I}}$ Cirilo Gruszynski ${ }^{\mathrm{II}}$ \\ Atelene Normann Kämpf ${ }^{\text {III }}$
}

\section{RESUMO}

O resíduo de rebaixamento de couro wet-blue $(R R)$, também denominado de "serragem de couro", resulta do processo de padronização do couro na indústria de curtimento. Na virada do século, a indústria nacional descartou cerca de 131 mil toneladas do RR na natureza. Neste estudo, investigou-se a possibilidade de uso de RR como um componente de substratos para plantas ornamentais de jardim. Mudas de Tagetes patula L. "Aurora” foram cultivadas em recipientes de $6 \mathrm{~cm}$ de altura e $216 \mathrm{~mL}$ de volume, contendo $R R+$ a mistura CACV (casca de arroz carbonizada e vermiculita superfina, $6: 1, v: v$ ) nas seguintes proporções volumétricas: 0:1 (100\% CACV), 1:3, 1:1, 3:1, 1:0 (100\% RR). As mudas foram cultivadas por 23 dias, até o ponto de transplante. A caracterização dos substratos testados baseou-se nos valores de $\mathrm{pH}$, salinidade, densidade seca e nas curvas de retenção de água. A adição de RR reduziu a densidade, aumentou a porosidade e a água retida nas misturas, proporcionando boas condições físicas para o desenvolvimento das mudas de Tagetes. A elevada salinidade do $R R\left(>7 g L^{-1}\right.$ como $\left.\mathrm{KCl}\right)$ e o baixo valor de $\mathrm{pH}$ natural do resíduo $\left(3,7\right.$, em $\left.\mathrm{H}_{2} \mathrm{O}\right)$ são características que precisam ser observadas nesta proposta de uso. De forma geral, as mudas mostraram boa tolerância à presença de RR até fração de $50 \%$ da mistura. Aumentando a proporção do resíduo, as plantas apresentaram tombamento, menor comprimento do sistema de raízes e menor estabilidade do torrão, que se desagregava ao ser retirada a muda para transplante. Os resultados sugerem a possibilidade de uso de $R R$ como componente de substrato para plantas, desde que observados suas características limitantes e a adição em volumes menores que $50 \%$ na mistura.

Palavras-chave: aproveitamento de resíduos sólidos; condicionador de substrato; produção de mudas em recipiente: salinidade.

\begin{abstract}
The industrial wet-blue leather standardization process generates a by-product called leather sawdust (RR). At the beginning of this century, the Brazilian tanning industry rejected about 131 thousand tons of $R R$ in the environment. The present study investigated the possibility of using $R R$ as a component for growing media. Seedlings of Tagetes patula $\mathbf{L}$. 'Aurora' were transplanted in 24 cell packs $(216 \mathrm{ml}$ each cell) containing blends of $R R$ and the mixture CACV (carbonized rice husks: fine vermiculite; $6: 1-v: v)$ in the following volumetric proportions: 0:1 (100\% CACV) , 1:3, 1:1, 3:1, 0:1 (100\% RR). The mixes were analyzed concerning $\mathrm{pH}$ value, salinity, bulk density and water retention curves. Increasing $R R$ fraction reduced bulk density while increased the total porosity and the amount of water in micropores. The high salt content of $R R\left(>7 \mathrm{~g} \mathrm{~L}^{-1}\right.$ as $\left.\mathrm{KCl}\right)$ and its natural low $\mathrm{pH}$ value $(3,7 \mathrm{em}$ $\mathrm{H}_{2} \mathrm{O}$ ) can reduce plant development and therefore must be taken in to account. The results suggest the use of RR as a component for growing media in amounts up to $50 \%$ in volume.
\end{abstract}

Key words: discard of solid residues, substrate conditioner, plug production, salinity.

\section{INTRODUÇÃO}

A indústria coureiro-calçadista e a produção de mudas vegetais em ambiente protegido são atividades de elevada importância econômica e social para o Estado. Aquela se caracteriza por ser geradora de resíduos, enquanto esta busca, nos resíduos industriais, os necessários componentes para elaboração de substratos para plantas.

\footnotetext{
IAssociação Sulina de Crédito e Assistência Rural, Associação Riograndense de Empreendimentos de Assistência Técnica e Extensão Rural (ASCAR/EMATER). Porto Algre, RS, Brasil. E-mail: rdaudt@hotmail.com.

IIASCAR/EMATER. Porto Alegre, RS, Brasil. E-mail: cirilo@cultivodeflores.com.br.

IIIniversidade Federal do Rio Grande do Sul (UFRGS). Rua Prof. Pedro Santa Helena, 480, 91410-150, Porto Alegre, RS, Brasil. E-mail: atelene@pesquisador.cnpq.br. Autor para correspondência.
} 
O setor coureiro-calçadista do Rio Grande do Sul conta com cerca de 130 indústrias de processamento do couro. Como conseqüência dos processos industriais, produz-se grande quantidade de resíduos sólidos, que podem ser não-curtidos (isentos de cromo) ou curtidos (a presença de cromo é facultativa, conforme o processo de curtimento). As raspas ou serragem de rebaixamento do couro wet-blue (RR) representam 90\% dos resíduos sólidos cromados provenientes do processo de curtimento. A designação wet-blue refere-se à pele bovina que sofreu o primeiro processo de transformação no curtume, através de um banho de cromo, que a deixa molhada e com tom azulado (BNDS, 2006). O rebaixamento, que visa à padronização de sua espessura, produz em média 4,5kg de RR por pele assim tratada (GUTTERRES, 1996). MARTINES (2005) cita que, em 2003, o Brasil comercializava cerca de 35 milhões de unidades de pele bovina por ano.

Serragem e pó-de-couro, provenientes de couro curtido ao cromo, são identificados pelo código K194 do Anexo B, da norma da ABNT NBR 10.004 (ASSOCIAÇÃO BRASILEIRA DE NORMAS TÉCNICAS, 2004), onde estes resíduos são classificados como pertencentes à Classe I, ou seja: perigosos, pelo alto teor de cromo hexavalente presente. Por essa razão, o destino desse resíduo é considerado um problema a ser resolvido: sua deposição diretamente em solo agrícola apresenta restrições (GUTTERRES, 1996) e o uso de aterros controlados é uma medida provisória, até que surjam melhores alternativas. Em 1993, Rodrigues e colaboradores se referiam ao limite máximo de $1.000 \mathrm{~kg}$ de Cr por hectare, aceito pela Fundação Estadual de Proteção Ambiental do Estado do Rio Grande do Sul-FEPAM (KRAY, 2001). A partir do final do século 20, as questões ambientais relacionadas com o descarte dos resíduos têm ocupado a atenção da cadeia produtiva do couro, dos órgãos governamentais e das instituições de pesquisa (RUPPENTHAL, 2001)

Outro setor de destaque, tanto no Rio Grande do Sul como no Brasil, é o de agronegócios, onde se insere a produção de plantas de interesse econômico em ambiente protegido. Mudas de hortaliças, frutíferas, florestais, ornamentais e de culturas agrícolas, como fumo e café, são produzidas em "substrato para plantas”, o produto usado como meio de crescimento, em substituição ao solo, no cultivo fora dele (GONCZAROWSKA, 2001). KÄMPF (2004) refere-se à grande demanda anual deste insumo, a exemplo da fumicultura (130 $\left.\mathrm{mil} \mathrm{m}^{-3}\right)$, da silvicultura $\left(125 \mathrm{mil} \mathrm{m}^{-3}\right) \mathrm{e}$ da citricultura (100 $\mathrm{mil} \mathrm{m}^{-3}$ ).

A elaboração de substratos, seja artesanal ou industrial, baseia-se na seleção de materiais leves e porosos. Além de adequadas características físicas, químicas e biológicas, as matérias primas devem estar disponíveis regularmente, em volumes suficientes e com baixo custo de aquisição e transporte (KÄMPF, 2000). FERMINO (1996) aponta a elaboração de substratos como um mercado potencial para resíduos da agroindústria, já que podem fornecer matérias-primas para a composição desses substratos. O resíduo RR atende a várias dessas exigências mencionadas: é leve, poroso, disponível em grandes volumes, com baixo custo de aquisição e transporte. Sua principal limitação se refere ao alto teor em cromo. Entretanto, não sendo destinadas ao consumo alimentar, plantas ornamentais e florestais poderiam ser produzidas em substratos feitos com resíduos industriais, contendo eventuais níveis mais elevados de metais tóxicos. O descarte deste tipo de material no ambiente, de forma diluída, através das mudas, reduziria o risco ambiental, se comparado à concentração em grandes depósitos ou aterros inadequados.

Avaliações preliminares de amostras de RR indicaram que este resíduo apresenta alta salinidade e baixo valor de $\mathrm{pH}$, condições limitantes para ser usado puro como substrato para plantas, conforme padrões referidos por HANDRECK \& BLACK (1999). KRAY (2001) analisou RR, com objetivo de testar seu uso no solo a campo, e encontrou $24 \mathrm{~g}$ de cromo por quilo de matéria seca de RR. Com base nas informações deste autor, calculou-se que, ainda que fosse possível produzir mudas de plantas ornamentais com substrato $100 \%$ de RR, por exemplo, em recipientes de $216 \mathrm{~mL}$ de volume, e se tais mudas fossem transplantadas para o campo, em espaçamento 15 x $15 \mathrm{~cm}$, o aporte de cromo ao solo corresponderia a três décimos da quantidade máxima de Cr permitida pela FEPAM. No caso de mudas de eucalipto, produzidas em tubetes com o mesmo volume, plantadas no espaçamento de 1,5 x 1,5m, estariam sendo colocados, aproximadamente, $3 \mathrm{~kg}$ de cromo/hectare ( $0,3 \%$ do limite permitido), descartando cerca de $125 \mathrm{~kg}$ do resíduo RR.

Com base nas hipóteses acima levantadas, o presente trabalho investiga a possibilidade de emprego do resíduo RR como um componente na elaboração de substratos para plantas ornamentais, usando como modelo a produção de mudas de Tagetes patula, uma planta florífera para uso em jardins.

\section{MATERIAL E MÉTODOS}

O estudo foi realizado no Laboratório de Biotecnologia em Horticultura da Faculdade de Agronomia da UFRGS, em Porto Alegre/RS, no período de 2000 a 2001. O resíduo utilizado nesse experimento 
foi obtido em curtume da região do Vale dos Sinos/RS. Ainda na indústria, o material foi compactado em blocos para a redução do volume e facilidade de transporte e armazenamento. No laboratório, a amostra foi umedecida e descompactada manualmente, triturada e peneirada (abertura da malha 9mm), apresentando, inicialmente, as seguintes características: densidade (seca) $=130 \mathrm{~g} \mathrm{~L}^{-1}$, $\mathrm{pH}\left(\mathrm{H}_{2} \mathrm{O}\right)=3,7$; salinidade $=7,5 \mathrm{~g} \mathrm{~L}^{-1}$ (expressa como $\mathrm{KCl}$ ).

Como tratamentos, foram usadas misturas de RR e CACV (casca de arroz carbonizada + vermiculita superfina-6:1v:v) nas seguintes proporções volumétricas: 0:1 (100\% CACV), 1:3, 1:1, 3:1, 1:0 (100\% RR). Na caracterização dos cinco tratamentos (Tabela 1), foram usados os seguintes atributos e métodos de análises: densidade seca, valor de $\mathrm{pH}\left(\mathrm{em} \mathrm{H}_{2} \mathrm{O}, 1\right.$ :2,5 v:v) e salinidade (relação 1:10 massa:volume, expressa como $\mathrm{KCl}$ ), conforme métodos descritos em RÖBER \& SCHALLER (1985) e transcritos em BELLÉ (1990); curvas de liberação de água (DE BOODT \& VERDONCK, 1972), determinando-se os valores de porosidade total (PT), espaço de aeração (EA), água facilmente disponível (AFD), água tamponante (AT) e água remanescente a $100 \mathrm{hPa}\left(\mathrm{AR}_{100}\right)$, conforme demonstrado em GROLLI (1991). A quantificação dos macro, meso e microporos foi baseada nos valores de $\mathrm{EA}$ (macro), AFD + AT (meso) e $\mathrm{AR}_{100}$ (microporos), adaptando-se os conceitos às classificações de HAYNES \& GOH (1978), DRZAL et al. (1999) e da International PEAT SOCIETY (2004). A Relação P/S, também chamada de Razão de Vazios (ROWELL, 1994), foi calculada através da divisão do volume de poros (PT) pelo volume de sólidos (volume total - PT). O valor original de $\mathrm{pH}$ das misturas foi corrigido com $\mathrm{KOH}$ ou $\mathrm{H}_{2} \mathrm{SO}_{4}$, conforme o caso, visando a aproximar os valores da faixa entre 5,5 e 6,0, indicada por BAILEY et al. (1999) para cultivos em substrato à base de material orgânico.

Mudas de Tagetes patula L. “Aurora”, com quatro semanas de idade, foram transplantadas para recipientes (plugs) com 6cm de altura e $216 \mathrm{~mL}$ de volume (uma planta por plug), contendo os tratamentos da tabela 1 . O cultivo foi realizado sobre bancada em casa de vegetação, seguindo o delineamento experimental de blocos casualizados, com quatro repetições e 20 plantas por parcela, totalizando 400 plantas (5 tratamentos x 4 blocos x 20 plantas por parcela), além das bordaduras. Após 23 dias de crescimento, quando a maioria das mudas apresentava a primeira flor aberta, foram tomadas aleatoriamente 16 plantas em cada parcela para realizar as seguintes mensurações: 1 . comprimento máximo de raiz; 2 . comprimento do caule entre os cotilédones e a folha mais nova; 3 . percentual de plantas por parcela que permaneceram eretas, ou seja, não tombaram, permanecendo firmes; 4. percentual de plantas por parcela, cujos torrões mantiveram-se agregados na retirada da muda para avaliação. No substrato dos quatro recipientes restantes de cada parcela experimental, foram analisados os valores de $\mathrm{pH}$ e salinidade, ao final do cultivo. Os resultados foram submetidos a análises de variância, correlação e regressão, com auxílio dos programas SANEST e SAS.

\section{RESULTADOS E DISCUSSÃO}

As plantas cresceram e floresceram em todos os tratamentos, demonstrando variações atribuídas aos substratos. Estes se caracterizavam especialmente por sua extrema leveza: os componentes misturados apresentavam baixa densidade seca $\left(\mathrm{RR}=130 \mathrm{~g} \mathrm{~L}^{-1} \mathrm{e}\right.$ $\mathrm{CACV}=157 \mathrm{~g} \mathrm{~L}^{-1}$ ) e o acréscimo de $\mathrm{RR}$ reduziu mais a densidade nas misturas (Tabela 1 ), de forma linear entre tais limites $\left(r^{2}=0,96 ; y=160,46-29,57 x ; p \leq 0,01\right)$. Tais valores se encontram na faixa de densidade considerada adequada ao cultivo em recipientes de poucos centímetros de altura (KÄMPF, 2000). De forma similar, RR e CACV apresentavam alta porosidade total (respectivamente, 93 e 85\% do volume). O uso de RR

Tabela 1 - Valores de $\mathrm{pH}$, salinidade e densidade seca $\left(\rho_{\mathrm{s}}\right)$ dos tratamentos testados.

\begin{tabular}{|c|c|c|c|c|c|c|}
\hline Tratamentos* & Fração de RR & $\mathrm{pH}$ natural & PH corrigido & $\begin{array}{l}\text { salinidade no início do } \\
\text { cultivo }\end{array}$ & $\begin{array}{l}\text { salinidade ao final do } \\
\text { cultivo }\end{array}$ & $\rho_{\mathrm{s}}$ \\
\hline & (\% volume) & $\left(\mathrm{H}_{2} \mathrm{O}\right)$ & $\left(\mathrm{H}_{2} \mathrm{O}\right)$ & $\left(\mathrm{g} \mathrm{L}^{-1}\right)$ & $\left(\mathrm{g} \mathrm{L}^{-1}\right)$ & $\left(\mathrm{g} \mathrm{L}^{-1}\right)$ \\
\hline 1CACV & 0 & 7,8 & $6,8 \mathrm{a} * *$ & $1,1 \mathrm{e}$ & $0,5 e$ & $157 a$ \\
\hline 1RR:3CACV & 25 & 5,6 & $5,6 b$ & $2,4 d$ & $1,6 \mathrm{~d}$ & $157 a$ \\
\hline 1RR:1CACV & 50 & 4,9 & $5,2 \mathrm{c}$ & $3,9 c$ & $2,4 \mathrm{c}$ & $146 b$ \\
\hline 3RR:1CACV & 75 & 4,1 & $4,9 \mathrm{c}$ & $5,1 b$ & $3,0 b$ & $139 b$ \\
\hline $1 \mathrm{RR}$ & 100 & 3,7 & $5,0 \mathrm{c}$ & $7,5 a$ & 3,3a & $130 c$ \\
\hline
\end{tabular}

* CACV = casca de arroz carbonizada + vermiculita, na proporção volumétrica de 6:1; RR = Raspa de couro wet-blue

** Médias seguidas de mesma letra nas colunas não diferem entre si pelo teste de Tukey $(\mathrm{p}=0,01)$. 
aumentou a porosidade total nas misturas de forma linear $\left(r^{2}=0,71 ; y=86,67+7,18 x ; P \leq 0,001\right)$ entre os limites citados. Mantendo-se os mesmos componentes, o incremento na porosidade se correlaciona com a redução na densidade $\left(\mathrm{r}^{2}=0,70 ; \mathrm{P} \leq 0,02\right)$, como esperado, confirmando as observações de HANNAN et al. (1981). Como conseqüência do aumento na porosidade, a presença de RR nas misturas elevou a razão de vazios, que variou desde 5 (em 1CACV) até 14 (1RR), com valores intermediários de 9 (em 1RR : 3CACV), 10 (em 3RR: 1CACV) e 12 (em 1RR:1CACV).

Com relação às características de economia hídrica (Figura 1), foram encontrados elevados volumes de espaço de aeração nas cinco misturas (entre 51 e $57 \%$ ), enquanto os volumes de AFD (entre 13 e 17\%) ficaram abaixo da faixa de 24 a $40 \%$ idealizada por DE BOODT \& VERDONCK (1972), porém dentro da faixa considerada de bom desempenho por FONTENO et al. (1981) para o cultivo com irrigação freqüente (até duas vezes ao dia). De maneira geral, a porosidade nos tratamentos mostrou-se adequada para o cultivo em recipientes de pouca altura, considerando que, em tais recipientes, o menor potencial gravitacional reduz a drenagem livre, proporcionando, assim, maior retenção de água (MILKS et al., 1989).

Em todos os tratamentos, a maior fração da porosidade correspondeu aos macroporos (entre 51 e $57 \%$ do volume) (Tabela 2). No tratamento $1 \mathrm{CACV}$, observou-se que meso e microporos apresentaram volumes iguais (17\%). Essa relação foi alterada pela presença de RR nas misturas, que aumentou o volume de microporos, reduzindo o de mesoporos. Considerando que os macroporos correspondem à

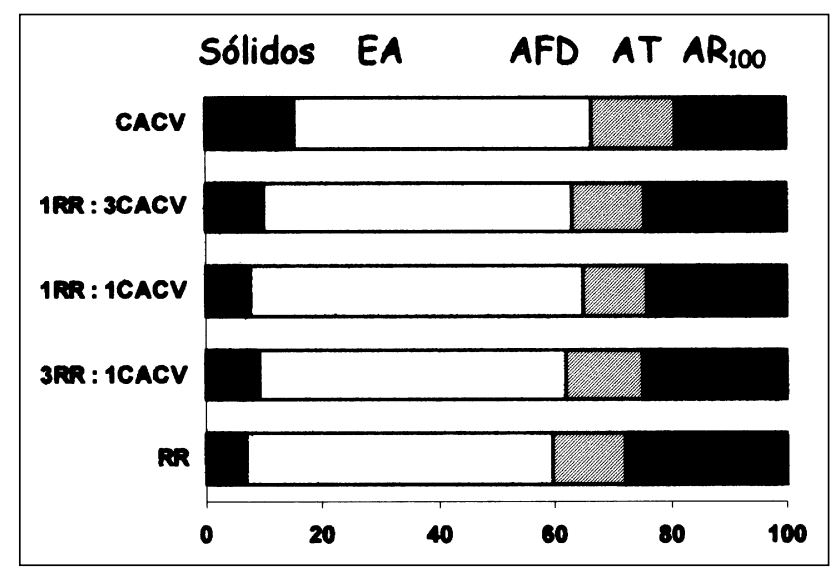

Figura 1 - Características dos substratos formados por RR (serragem de couro wet blue) e CACV (casca de arroz carbonizada e vermiculita, 6:1 v:v): porcentagem do volume ocupado por sólidos, espaço de aeração (EA), água facilmente disponível (AFD), água tamponante (AT) e água retida em $100 \mathrm{hPa}\left(\mathrm{AR}_{100}\right)$ fração de poros que se enchem de ar imediatamente após a irrigação, por drenagem livre, que os mesoporos correspondem ao volume de água disponível às plantas em tensão inferior a $100 \mathrm{hPa}$ e que os microporos correspondem ao volume de água retido sob tensão igual ou maior que $100 \mathrm{hPa}$, conclui-se que a presença de RR nas misturas aumentou a retenção de água pelo substrato, nas tensões mais altas. É possível que parte dessa água de microporos esteja relacionada à capacidade de hidratação das partículas do couro, em poros internos.

Quanto ao valor de $\mathrm{pH}$ natural, RR mostra reação ácida $(3,7)$, enquanto CACV reage de forma levemente alcalina $(7,5)$. Com a correção, essa diferença foi reduzida, passando, respectivamente, para 5,0 e 6,8. Mesmo assim, os valores mantiveram-se ainda fora da faixa considerada como ideal para substratos orgânicos. Segundo BAILEY et al. (2000), o pH abaixo de 5,4 eleva o risco de ocorrência de toxicidade na planta, devido ao excesso de absorção de ferro, zinco e cobre, e valores acima de 6,4 podem favorecer deficiências de ferro e boro nas plantas cultivadas em substratos. Relacionando o valor de $\mathrm{pH}$ e o crescimento das plantas, obteve-se correlação linear positiva entre o $\mathrm{pH}$ e o comprimento máximo de raízes $\left(r^{2}=0,98, P \leq 0,001\right)$, entretanto, sem expressão no desenvolvimento da parte aérea das plantas. Apesar de os valores de $\mathrm{pH}$ estarem fora da faixa considerada ideal por BAILEY e colaboradores, não foram verificados sintomas nutricionais de deficiência e/ou de toxicidade nas plantas, em todos os tratamentos. Como os valores de $\mathrm{pH}$ mais baixos estavam associados à presença de RR, com salinidade mais elevada, questiona-se se o menor crescimento das raízes estaria realmente correlacionado aos valores baixos de $\mathrm{pH}$ ou à salinidade mais alta no componente RR.

A salinidade do resíduo $\mathrm{RR}\left(7,5 \mathrm{~g} \mathrm{~L}^{-1}\right)$ é considerada excessivamente alta, enquanto a de CACV (1,1 $\left.\mathrm{g} \mathrm{L}^{-1}\right)$ é considerada de baixa a moderada, segundo o critério de RÖBER \& SCHALLER (1985). O uso de RR aumentou linearmente o valor da salinidade, de forma proporcional à fração deste resíduo na mistura $\left(\mathrm{y}=0,86+0,062 \mathrm{x} ; \mathrm{r}^{2}=0,98\right.$; $\mathrm{P} \leq 0,001)$. De modo geral, a alta salinidade comprometeu o desenvolvimento das plantas de T. patula: o crescimento foi menor, à medida que o substrato apresentava maior fração de RR; as plantas em 1RR não conseguiam se manter eretas para o transplante. As análises estatísticas mostraram correlação linear negativa entre a salinidade e o comprimento máximo de raiz $\left(\mathrm{r}^{2}=-0,93, \mathrm{P} \leq 0,001\right)$, percentual de plantas eretas $\left(r^{2}=-0,99, P \leq 0,001\right)$, percentual de torrões que permaneceram inteiros 
Tabela 2 - Volume dos substratos ocupado por macro, meso e microporos.

\begin{tabular}{|c|c|c|c|c|c|}
\hline \multirow{2}{*}{ Tratamentos* } & Fração de RR & Sólidos & Macroporos & Mesoporos & Microporos \\
\hline & \multicolumn{5}{|c|}{$\%$ volume } \\
\hline 1CACV & 0 & 15 & 51 & 17 & 17 \\
\hline 1RR:3CACV & 25 & 10 & 53 & 15 & 22 \\
\hline 1RR:1CACV & 50 & 8 & 57 & 13 & 22 \\
\hline 3RR:1CACV & 75 & 9 & 53 & 15 & 23 \\
\hline $1 \mathrm{RR}$ & 100 & 7 & 53 & 14 & 27 \\
\hline
\end{tabular}

* $\mathrm{CACV}=$ casca de arroz carbonizada + vermiculita, na proporção volumétrica de 6:1; RR = raspa de couro wet-blue

na retirada da muda do recipiente $\left(\mathrm{r}^{2}=-0,90, \mathrm{P} \leq 0,001\right) \mathrm{e}$ o desenvolvimento da parte aérea $\left(\mathrm{r}^{2}=-0,82, \mathrm{P} \leq 0,01\right)$. Além do alto teor em cromo, a salinidade do resíduo RR está também relacionada à presença de sódio, pela utilização de $\mathrm{NaCl}$ na salga das peles para sua armazenagem e conservação. Analisando amostras de RR, KRAY (2001) encontrou 4,3g de sódio e 24g de cromo por quilograma de matéria seca e FERREIRA et al. (2003) encontraram $7 g$ de sódio e $21 \mathrm{~g}$ de cromo por quilograma de matéria seca. Considerando a densidade seca do resíduo, tais valores representam cerca de 0,6 a 0,9g em sódio e de 2, 7 a 3,1g em cromo no volume de um litro de RR.

\section{CONCLUSÃO}

O estudo demonstrou a possibilidade do cultivo em substratos contendo serragem de rebaixamento de couro (RR). De forma geral, as mudas de Tagetes patula L. “Aurora” mostraram boa tolerância à presença de RR até fração volumétrica de $50 \%$ da mistura. Aumentando a proporção do resíduo, as plantas apresentaram tombamento e menor comprimento do sistema de raízes, diminuindo a estabilidade do torrão. Como condicionador nas misturas, RR promoveu a redução da densidade e o aumento da porosidade, incrementando em especial os volumes de macro e microporos. Sua elevada salinidade, porém, mostrou ser limitante ao crescimento vegetal. Pelo exposto, a sugestão de uso restringe-se a, no máximo, 50\% do volume nas misturas.

São indicados novos estudos para esse tema, envolvendo, entre outros aspectos, análises químicas da solução percolada durante o cultivo, para avaliar seu risco ambiental na área de produção. Tendo em vista as características do resíduo, sugere-se que os testes sejam realizados com espécies ornamentais e/ou florestais, que tenham resistência à salinidade e afinidade a substratos com baixa densidade e alta porosidade.

\section{AGRADECIMENTOS}

Ao Conselho Nacional de Desenvolvimento Científico e Tecnológico (CNPq) e à ASCAR/EMATER-RS, pelas bolsas de pós-graduação e de pesquisa.

\section{REFERÊNCIAS}

ASSOCIAÇÃO BRASILEIRA DE NORMAS TÉCNICAS. Resíduos sólidos - Coletânea de Normas. ABNT NBR 10004, ABNT NBR 10005, ABNT NBR 10006, ABNT NBR 1007. 2.ed. Rio de Janeiro, 2004. 124p.

BAILEY, D.A. et al. Greenhouse substrates and fertilization. Raleigh: North Carolina State University. Capturado em 10 ago, 2000. Online. Disponível na Internet http://www.ces.ncsu.edu/depts/hort/floriculture/plugs/ ghsubfert.pdf .

BAILEY, D.A. et al. Water considerations for container production of plants. Horticulture Information Leaflet. Raleigh: North Carolina State University, NC Cooperative Extension Service. n. 557, 1999. Capturado em 12 ago, 2000. Online. Disponível na Internet http://www2.ncsu.edu/ floriculture/

BELLÉ, S. Uso da Turfa “Lagoa dos Patos” (Viamão/RS) como substrato hortícola. 1990. 143f. Dissertação (Mestrado em Fitotecnia) - Programa de Pós-graduação em Agronomia, Universidade Federal do Rio Grande do Sul, Porto Alegre.

BNDS. Glossário de termos usados em atividades Agropecuárias, Florestais e Ciências Ambientais. Capturado em $10 \mathrm{abr}$, 2006. Online. Disponível na Internet http:// www.bnds.gov.br/conhecimento/livro_glossario/glossario.pdf.

DE BOODT, M; VERDONCK, O. The physical properties of the substrates in horticulture. Acta Horticulturae, Wageningen, v.26, p.37-44, 1972.

DRZAL, M.S. et al. Pore fraction analysis: a new tool for substrate testing. Acta Horticulturae, Wageningen, v.481, p.43-53, 1999.

FERMINO, M.H. Aproveitamento de resíduos industriais e agrícolas como alternativas de substratos hortícolas. 1996. 90f. Dissertação (Mestrado em Fitotecnica) - Programa de Pós-graduação em Agronomia, Universidade Federal do Rio Grande do Sul, Porto Alegre. 
FERREIRA, A.S. et al. Alterações de atributos químicos e biológicos de solo e rendimento de milho e soja pela utilização de resíduos de curtume e carbonífero. Revista Brasileira de Ciência do Solo, Viçosa, v.27, n.4, p.755-763, 2003.

FONTENO, W.C. et al. Physical properties of three container media and their effect on poinsettia growth. Journal of the American Society for Horticultural Science, Alexandria, v.106, p.736-741, 1981.

GONCZAROWSKA, R.A. Substrato para plantas e legislação. Boletim Informativo da Sociedade Brasileira de Ciência do Solo, Viçosa, v.26, p.10-12, 2001.

GROLLI, P.R. Composto de lixo domiciliar urbano como condicionador de substratos para plantas arbóreas. 1991. 126f. Dissertação (Mestrado em Fitotecnia) - Programa de Pós-graduação em Agronomia, Universidade Federal do Rio Grande do Sul, Porto Alegre.

GUTTERRES, M. Alternativas para destinação do resíduo do rebaixamento do couro wet-blue. Revista do Couro, Estância Velha, v.113, n.22, p.49-54, 1996.

HANDRECK, K.; BLACK, N. Growing media for ornamental plants and turf. Sydney: UNSWP, 1999. 448p.

HANNAN, J.J. et al. Bulk density, porosity, percolation and salinity control in shallow, freely draining, potting soils. Journal of the American Society of Horticultural Science, Alexandria, v.106, n.6, p.772-746, 1981.

HAYNES, R.J.; GOH, K.M. Evaluation of potting media for commercial nursery production of container-grown plants: IV - Physical properties of a range amendment peat-based media. New Zealand Journal of Agricultural Research, Wellington, v.21, p.449-456, 1978.

INTERNATIONAL PEAT SOCIETY, Commission III. Utilization of Peat and Peatlands in Agriculture. Annual
Report 2004. Capturado em 11 dez. 2005. Online. Disponível na Internet http://www.peatsociety.org/index.php?id=86

KÄMPF, A.N. Seleção de materiais para uso como substrato. In: KÄMPF, A.N. \& FERMINO, M.H. (Ed). Substrato para plantas, a base da produção vegetal em recipientes. Porto Alegre: Gênesis, 2000. p.139-145.

KÄMPF, A.N. Evolução e perspectivas do crescimento do uso de substratos no Brasil. In: BARBOSA, J.G. et al. (Ed.). Nutrição e adubação de plantas cultivadas em substrato. Viçosa: UFV, 2004. p.3-10.

KRAY, C.H. Efeitos da aplicação e da reaplicação de resíduos carbonífero e de curtume no solo e nas plantas. 2001. 90f. Dissertação (Mestrado em Fertilidade do Solo) Programa de Pós-graduação em Agronomia, Universidade Federal do Rio Grande do Sul, Porto Alegre.

MARTINES, A.M. Impacto do lodo de curtume nos atributos biológicos e químicos do solo. 2005. $74 \mathrm{f}$ Dissertação (Mestrado em Solos e Nutrição de Plantas) - Curso de Pós-graduação em Agronomia, USP-ESALQ. Capturado em 25 mar, 2006. Online. Disponível na Internet http:// www.teses.usp.br/teses/disponiveis/11/11140/tde-02082005132525/publico/AlexandreMartines.pdf .

MILKS, R.R et al. Hydrology of horticultural substrates: III. Predicting air and water content of limited-volume plug cells. Journal of the American Society of Horticultural Science, Alexandria, v.114, n.1, p.57-61. 1989.

RÖBER, R.; SCHALLER, K. Pflanzenernährung im Gartenbau. Stuttgart: Ulmer, 1985. 352p.

ROWELL, D.L. Soil science, methods and aplications. Essex: Longman Group, 1994. 344p.

RUPPEnTHAL, J.E. Perspectivas do setor couro do estado do Rio Grande do Sul. 2001. 109f. Dissertação.(Mestrado em Engenharia da Produção). Curso de Pós-graduação em Engenharia da Produção, Universidade Federal de Santa Catarina. 